\title{
EDITORIAL
}

\section{Diagnosis of ventilator-associated pneumonia: nonroutine tools for routine practice}

\section{S. Ewig}

During the past decade, remarkable efforts have been made to establish valid and reliable techniques for the diagnosis of ventilator-associated pneumonia (VAP). One of the most important findings consistently reported has been the limited value of traditional clinical criteria for the definition of pneumonia [1-3]. This has reinforced the need for the inclusion of additional diagnostic criteria derived from quantitative bacterial culture techniques. A histological diagnosis of pneumonia as independent reference for the calculation of diagnostic indices is only available in postmortem studies [4]. In fact, studies using postmortem histology as gold standard and fulfilling strict methodological requirements of lung tissue processing suggest that the diagnosis of VAP may be established in a realistic clinical setting with satisfactory accuracy by quantitative bacterial cultures [5-8]. It is, nevertheless, evident that postmortem studies select cases with ultimately fatal outcome, which do not reflect the whole spectrum of VAP. An irrefutable gold standard does not exist. As a result, clinical criteria remain crucial in routine practice as well as in studies evaluating different diagnostic techniques in the diagnosis of VAP.

It has been suggested that studies evaluating clinical and radiological criteria in the diagnosis of VAP should include quantitative scoring, in order to reflect clinical judgement more accurately [9]. In support of this view, a clinical pulmonary infection score (CPIS), which attempts to grade the likelihood of the presence of pneumonia, was shown to achieve high concordance rates with quantitative culture results [10]. Thus, a clinical estimate (and/or scoring) of the probability of the presence of pneumonia remains a mainstay for the diagnosis of VAP.

In light of the current controversy as to whether quantitative culture techniques are useful in routine practice $[9,11]$, two issues should be addressed: firstly, to what extent does aetiological diagnosis contribute independently to the diagnosis of VAP?; and secondly, can we rely on colony counts for treatment decisions? PUGIN et al. [10], using the above-mentioned CPIS consisting of six different clinical variables, reported a concordance of $93 \%$ between clinical and microbiological criteria for pneumonia. Similarly, AuBAS et al. [12] convincingly demonstrated the value of more complex clinical criteria than those traditionally used for the diagnosis of VAP. Thus, a quantitative culture result will independently establish the diagnosis of VAP in only a minority of cases. Accordingly, individual treatment decisions, in most cases, cannot rely exclusively on a quantitative

Correspondence: S. Ewig, Medizinische Universitätsklinik und Poliklinik Bonn, Innere Medizin/Kardiologie und Pneumologie, SigmundFreud-Str.25, 53105 Bonn, Germany. culture result. This would imply standardized cut-off values discriminating contamination or colonization from infection, allowing antibiotic therapy to be withheld at borderline low colony counts. Obviously, there is no generally accepted standardized cut-off value. Using analytical tools, and assuming that the potential harm of antibiotics is considerably low in most individual cases, it has been argued that antibiotic treatment will be indicated in most cases with intermediate and in all cases with high likelihood of pneumonia, even in the event of low colony counts [13]. To withhold antibiotics whilst awaiting results of a repeated evaluation is only justifiable in patients at low risk and with mild impairment [14]. The value of colony counts for treatment decisions may, therefore, be mainly restricted to confirmative results suggesting the presence of pneumonia. What then is the role of quantitative culture techniques in routine practice?

Clearly, microbial investigations are useful for guidance of antibiotic therapy after susceptibility testing, as well as for local epidemiological databases providing a framework for empirical therapy, although it will be difficult to assess the individual gains of an aetiological diagnosis with regard to the outcome. Other issues, such as the effect of quantitative microbial investigation on morbidity and hospital stay, may be clarified in the near future.

Another important question considering quantitative culture techniques for routine use is, which technique should be chosen as the preferred method for sampling of respiratory secretions? Nonbronchoscopic techniques include bronchial aspirates as well as a variety of "blind" catheter brush and (mini)lavage techniques. Bronchoscopic techniques are the protected specimen brush (PSB) or the conventional or "protected" bronchoalveolar lavage (BAL). Nonbronchoscopic techniques claim to achieve at least comparable diagnostic yields, and offer safety, easy handling as well as cost-savings as important advantages. Among these, simple quantitative bronchial aspirates appear to be especially attractive.

Accordingly, in this issue of the Journal, Bello et al. [15] present the results of a double-sheathed, balloontipped, plugged catheter (ACCU-CATH®) allowing a "blind" protected specimen brushing. They found no difference in the diagnostic yield as compared with bronchoscopic PSB and BAL, the sensitivities being 66, 59 and $56 \%$, respectively, and the specificities 91, 96 and $96 \%$, respectively. However, the use of ACCU-CATH® as well as nonbronchoscopic devices for mini-BAL, e.g. the Ballard-catheter [16], require significant individual skill and training. 
BARREIRo et al. [17], also in this issue of the Journal, report the results of protected BAL (PBAL), a doublelumen catheter providing a sterile irrigation lumen. Originally introduced and validated by MEDURI and co-workers $[18,19]$, this is the first confirmatory report on its value in the diagnosis of VAP. Using clinical criteria and significant colony counts in PSB as reference, a sensitivity of $87 \%$ and a specificity of $91 \%$ was achieved. Clearly, bronchoscopic PBAL represents, at present, the most sophisticated technique available. The concept of PBAL is to improve the diagnostic yield by combining the high sensitivity of BAL and the high specificity of the PSB. Other than this theoretical consideration, there is actually no evidence that PBAL is superior to any technique which would justify its routine use. However, an attempt at comparing PBAL with other techniques in a postmortem study, with histology as independent reference, would be worthwhile.

PSB has been studied most extensively, whereas BAL has been investigated considerably less often. Data on bronchial aspirates and other noninvasive techniques are quite limited. Prior to routine use, any technique should also have been validated by postmortem studies. In this regard, significant data are available only for PSB, BAL and bronchial aspirates. The reported diagnostic indices vary considerably. Current data do not prove any diagnostic technique to be superior to another. It is intriguing to observe that even very experienced study groups report contradictory findings, e.g. FAGON, Chastre and co-workers $[1,6,20]$ continuously reproduce excellent results for PSB, but cannot confirm an equivalent value of bronchial aspirates [21]; MEDURI and co-workers [18, $19]$, on the other hand, report favourable results for BAL or PBAL, but not for PSB; PAPAZIAN et al. [8], however, find bronchial aspirates to be considerably superior to PSB. TORRES and co-workers [22-24], having reported comparable results for PSB and BAL as well as for bronchial aspirates in a series of studies, did not find any technique to be useful in a postmortem study of a population with prolonged antibiotic treatment [25]. There is no satisfactory explanation for these conflicting results. Possible clues may be divergent susceptibility patterns of pathogens in the intensive care unit (ICU), different antibiotic pretreatment regimen, and variations in the microbiological and/or histological work-up. Overall, the diversity of reported diagnostic yields hints at individual local settings as systematic confounders, which may generally impede direct comparisons. Since no standardization can be achieved, no general recommendation can be made. Instead, it seems reasonable to argue that each ICU setting should establish its own preferred diagnostic techniques.

The method of sampling of respiratory secretions should also be individualized according to clinical and institutional requirements. Settings where bronchoscopic techniques are not available should establish a nonbronchoscopic technique. Furthermore, noninvasive techniques are preferably indicated in patients with severe bleeding disorders or with septic shock. Studies confirming the value of nonbronchoscopic techniques, therefore, prove to be of high clinical interest [7, 8, 16, 26-31]. Bronchoscopy, on the other hand, offers the advantage of revealing important additional diagnostic information by direct visualization of the tracheobronchial tree, e.g. on purulent secretions, bronchial bleeding, or bronchial obstruction. Moreover, a careful bronchial toilette can be performed. For these reasons, bronchoscopy should not be generally replaced by nonbronchoscopic techniques.

A final important concern exists in terms of financial considerations. In our view, cost-effectiveness cannot appropriately be assessed by rough comparison of costs for catheters, bronchoscopy and cultures. Any of the diagnostic techniques in question will at least temporarily deserve to be considered as cost-effective if they provide satisfactory information to the clinician. He will have to decide to what extent diagnostic techniques can be simplified without significant loss of diagnostic information.

In conclusion, quantitative culture testing remains an important advance in the diagnosis of ventilator-associated pneumonia. It may prove of limited value for the individual management, but clearly represents the most valid technique for the identification of pathogen and susceptibility patterns in the local intensive care unit. It is crucial, however, to recognize that we are dealing with a poorly standardized technique. The introduction of quantitative culture testing into routine practice, therefore, requires continuous individual efforts to establish and preserve satisfactory diagnostic yields. Whatever diagnostic technique is used, it will require a large body of experience to be appropriately applied. In order to assure an optimal antibiotic policy in the intensive care unit, the clinician is invited to meet the challenge of using nonroutine tools for routine practice.

\section{References}

1. Fagon JY, Chastre J, Hance AJ, et al. Detection of nosocomial lung infection in ventilated patients: use of a protected specimen brush and quantitative culture techniques in 147 patients. Am Rev Respir Dis 1988; 138: 110-116.

2. Fagon JY, Chastre J, Hance AJ, Domart Y, Trouillet JL, Gibert C. Evaluation of clinical judgement in the identification and treatment of nosocomial pneumonia in ventilated patients. Chest 1993; 103: 547-553.

3. Wunderink RG, Woldenberg LS, Zeiss J, Day MD, Ciemiens J, Lacher DA. The radiologic diagnosis of autopsy-proved ventilator-associated pneumonia. Chest 1992; 101: 458-558.

4. Pingleton SK, Fagon JY, Leeper KV. Patient selection for clinical investigation of ventilator-associated pneumonia: criteria for evaluating diagnostic techniques. Chest 1992; 102: 553S-556S.

5. Rouby JJ, Martin De Lassale E, Poete P, et al. Nosocomial bronchopneumonia in the critically ill: histologic and bacteriologic aspects. Am Rev Respir Dis 1992; 146: 1059_ 1066.

6. Chastre J, Fagon JY, Bornet-Lesco M, et al. Evaluation of bronchoscopic techniques for the diagnosis of nosocomial pneumonia. Am J Respir Crit Care Med 1995; 152: 231-240.

7. Marquette $\mathrm{CH}$, Copin MC, Wallet F, et al. Diagnostic tests for pneumonia in ventilated patients: prospective evaluation of diagnostic accuracy using histology as a diagnostic gold standard. Am J Respir Crit Care Med 1995; 151: 1878-1897.

8. Papazian L, Thomas P, Garbe L, et al. Bronchoscopic or blind sampling techniques for the diagnosis of ventilator-associated pneumonia. Am J Respir Crit Care Med 1995; 152: 1982-1991. 
9. Niederman MS, Torres A, Summer W. Invasive diagnostic testing is not needed routinely to manage suspected ventilator-associated pneumonia. Am J Respir Crit Care Med 1994; 150: 565-569.

10. Pugin J, Auckenthaler R, Mili N, Janssens JP, Lew PD, Suter PM. Diagnosis of ventilator-associated pneumonia by bacteriologic analysis of bronchoscopic and nonbronchoscopic "blind" bronchoalveolar lavage fluid. Am Rev Respir Dis 1991; 143: 1121-1129.

11. Chastre J, Fagon JY. Invasive diagnostic testing should be routinely used to manage ventilated patients with suspected pneumonia. Am J Respir Crit Care Med 1994; 150: $570-574$.

12. Aubas S, Aubas P, Capdevila X, Darbas H, Roustan JP, DuCailar J. Bronchoalveolar lavage for diagnosing bacterial pneumonia in mechanically-ventilated patients. Am J Respir Crit Care Med 1994; 149: 860-866.

13. Baker AM, Bowton DL, Haponik EF. Decision making in nosocomial pneumonia: an analytic approach to the interpretation of quantitative bronchoscopic cultures. Chest 1995; 107: 85-95.

14. Dreyfuss D, Mier L, Le Bourdelles G, et al. Clinical significance of borderline quantitative protected brush specimen culture results. Am Rev Respir Dis 1993; 147: 946-951.

15. Bello S, Tejada A, Chacon E, et al. "Blind" protected specimen brushing versus bronchoscopic techniques in the etiological diagnosis of ventilator-associated pneumonia. Eur Respir J 1996; 9: 1494-1499.

16. Kollef MH, Bock KR, Richards RD, Hearns ML. The safety and diagnostic accuracy of minibronchoalveolar lavage in patients with suspected ventilator-associated pneumonia. Ann Intern Med 1995; 122: 743-748.

17. Barreiro B, Dorca J, Manresa F, et al. Protected bronchoalveolar lavage in the diagnosis of ventilator-associated pneumonia. Eur Respir J 1996; 9: 1500-1507.

18. Meduri GU, Beals DH, Maijub AG, Baselski V. Protected bronchoalveolar lavage: a new bronchoscopic technique to retrieve uncontaminated distal airway secretions. Am Rev Respir Dis 1991; 143: 855-864.

19. Meduri GU, Wunderink RG, Leeper KV, Beals DH. Management of bacterial pneumonia in ventilated patients: protected bronchoalveolar lavage as a diagnostic tool. Chest 1992; 101: 500-508.

20. Fagon JY, Chastre J, Domart Y, et al. Nosocomial pneumonia in patients receiving continuous mechanical ventilation: prospective analysis of 52 episodes with use of a protected specimen brush and quantitative culture technique. Am Rev Respir Dis 1989; 139: 877-884.

21. Jourdain B, Novara A, Joly-Guillou, et al. Role of quantitative cultures of endotracheal aspirates in the diagnosis of nosocomial pneumonia. Am J Respir Crit Care Med 1995; 152: 241-246.

22. Torres A, De La Bellacasa JP, Xaubet A, et al. Diagnostic value of quantitative cultures of bronchoalveolar lavage and telescoping plugged catheters in mechanically-ventilated patients with bacterial pneumonia. Am Rev Respir Dis 1989; 140: 306-310.

23. Torres A, Martos A, De La Bellacasa JP, et al. Specificity of endotracheal aspiration, protected specimen brush, and bronchoalveolar lavage in mechanicallyventilated patients. Am Rev Respir Dis 1993; 147: 952957.

24. El-Ebiary M, Torres A, Gonzalez J, et al. Quantitative cultures of endotracheal aspirates for the diagnosis of ventilator-associated pneumonia. Am Rev Respir Dis 1993; 148: 1552-1557.

25. Torres A, El-Ebiary M, Padro L, et al. Validation of different techniques for the diagnosis of ventilator-associated pneumonia: comparison with immediate postmortem pulmonary biopsy. Am J Respir Crit Care Med 1994; 149: 324-331.

26. Torres A, De la Bellacasa JP, Rodriguez-Roisin R, Jimenez De Anta MT, Agusti-Vidal A. Diagnostic value of telescoping plugged catheters in mechanically-ventilated patients with bacterial pneumonia using the Metras catheter. Am Rev Respir Dis 1988; 138: 117-120.

27. Papazian L, Martin C, Meric B, Dumon JF, Gouin F. Comparison of two methods of bacteriologic sampling of the lower respiratory tract: a study in ventilated patients with nosocomial bronchopneumonia. Crit Care Med 1989; 17: 461-464.

28. Pham LH, Brun-Buisson C, Legrand P, et al. Diagnosis of nosocomial pneumonia in mechanically-ventilated patients: comparison of a plugged telescoping catheter with the protected specimen brush. Am Rev Respir Dis 1991; 143: 1055-1061.

29. Papazian L, Martin C, Meric B, Dumon JF, Gouin F. A reappraisal of blind bronchial sampling in the microbiologic diagnosis of nosocomial bronchopneumonia. Chest 1993; 103: 236-242.

30. Jorda R, Parras F, Ibanez J, Reina J, Bergada J, Raurich JM. Diagnosis of nosocomial pneumonia in mechanically-ventilated patients by the blind protected telescoping catheter. Intensive Care Med 1993; 19: 377-382.

31. Marquette $\mathrm{CH}$, Georges $\mathrm{H}$, Wallet $\mathrm{F}$, et al. Diagnostic efficiency of endotracheal aspirates with quantitative bacterial cultures in intubated patients with suspected pneumonia: comparison with the protected specimen brush. Am Rev Respir Dis 1993; 148: 138-144. 